\title{
Screening of V617F mutation in JAK2 gene with acute myeloid leukemia in the Saudi population
}

\author{
Abdullah Farasani $i^{1,2} \otimes$ \\ ${ }^{1}$ Medical Research Center, Jazan University, Jazan, Saudi Arabia; ${ }^{2}$ Department of Medical Laboratory Technology, Faculty of Applied Medical \\ Sciences, Jazan University, Jazan, Saudi Arabia
}

Progress in pathogenesis and therapy of acute myeloid leukemia (AML) is presently accelerating. The Janus kinase 2 gene (JAK2) mutations are rare in de novo AML. The gene codes for the tyrosine kinase that has a significant role in the signal transduction in hematopoietic cells. The aim of this study was to induce V617F mutation in the JAK2 gene in the AML patients diagnosed in the Saudi population. In this case-control study, 100 AML patients and 100 healthy controls were recruited. Genotyping was performed with polymerase chain reaction followed with restriction fragment length polymorphism analysis. The mean age of the AML patients and healthy controls was found to be almost similar $(p=0.60)$. In this study, $15 \%$ of VF mutation was documented in the AML cases and none of the mutations were documented either in FF mutation in AML cases or VF and FF mutations in the healthy control subjects. VF mutations [VF vs VV; OR-18.79; (95\%Cls: $2.442-144.6)$ and $p=0.0001$; F vs V; OR-87.76; (95\% Cls: 11.76-654.7) and $p<0.0001]$ were found to be significantly associated when compared between AML cases and healthy controls. In conclusion, the V617F mutation showed the positive association in the AML patients diagnosed in the Saudi population.

Keywords: acute myeloid leukemia, V617F, JAK2 and Saudi population

Received: 06 October, 2021; revised: 05 December, 2021; accepted: 07 December, 2021; available on-line: 21 February, 2022

凶e-mail: aofarasani@jazanu.edu.sa

Abbreviations: AML, acute myeloid leukemia; HWE, Hardy Weinberg Equilibrium; JAK2, Janus kinase 2 gene; $\mathrm{H} 2$, Jak homology domain 2; ET, essential thrombocythemia; MMM, myeloid myelofibrosis metaplasia; PV, polycythemia Vera; PCR, Polymerase Chain Reaction; SNP, Single nucleotide polymorphism; V617F, valine617-phenylalanine

\section{INTRODUCTION}

Acute myeloid leukemia (AML) is a type of cancer which involves bone marrow, blood, and other tissues by proliferative, highly undifferentiated, slightly abnormal and sometimes immature, and mesenchymal cells (Döhner et al., 2015). AML is a highly heterogenous and CD34+CD38- myeloid progenitor hematopoietic malignant disorder (da Cunha Vasconcelos et al., 2021). The etiology of this disease is virtually unknown, but the relationship between environmental risk and genetic susceptibility is believed to be a potential trigger for the formation of AML (Botros et al., 2021). The rate of occurrence rises considerably with the age at about 35/1000000 people. AML is therefore more frequent among people over 60 years of age (Sariani et al., 2021). AML accounts for $10-20 \%$ of infant leukemia and less than $30 \%$ of adults have a survival rate of AML for 5 years. In addition, older persons with AML are poorly tolerated and contagious (Yuan et al., 2021). The acute promyelocytic leukemia variant should be treated as a distinct entity with distinct genetic defects, different treatment, and a better prognosis than patients with nonpromyelocytic variants, and the term AML applies to nonpromyelocytic variants (Hernandez-Valladares et al., 2021). A combination of anthracyclines and cytosine arabinoside in the normal $3 / 7$ regimen is the quality of care in community practice (Sasaki et al., 2021). AML has been identified as the sixth leading cause of death among a variety of malignancies. During diagnosis, AML patients exhibit 50$60 \%$ in chromosomal anomalies, and karyotyping plays a significant role in disease-related prognostic factors for care. Despite major advancements in the diagnostic and therapeutic processes, patients with AML have a poor prognosis (Farasani, 2019).

For the majority of genetic variants, gene mutations are the most common ones. Gene polymorphisms are commonly a cause of genetic diseases, but not always. Single nucleotide polymorphisms (SNPs) is the most common form of nucleotide variations found in humans, representing the most common base pair variation (Khan et al., 2016). Previous studies have identified many SNPs with leukemias and Janus kinase 2 (JAK2), was one of the SNPS documented with AML. The Janus Kinases (JAK) family of mammals includes four cytoplasmic tyrosine kinases (JAK1, JAK2, JAK3 and TYK2) recruited and activated by particular cytokine receptors on the surface of certain cells and receptors which are critical in normal and disordered hematopoiesis (Steensma et al., 2006). Previous studies showed that JAK2 tyrosine kinase has recurring somatic activating mutations in polycythemia vera (PV), essential thrombocythemia (ET), and myeloid myelofibrosis metaplasia (MMM). In the Jak homology domain 2 (JH2) pseudokinase field of JAK2, V617F mutation leads to the valine-phenylalanine replacement for codon 617 (Levine et al., 2005). Limited studies have been documented with V617F mutation in the JAK2 gene with AML and no studies have been carried out in the Saudi population. So, the current study was carried out in the Saudi population between AML patients and $\mathrm{V} 617 \mathrm{~F}$ mutation in the $J A K 2$ gene.

\section{MATERIALS AND METHODS}

In this case-control study, age and gender matching Saudi patients 100 AML patients and 100 healthy subjects were selected. All recruited samples were collected from Riyadh regional laboratory, Saudi Arabia. Both 
Table 1. Anthropometric information on the patients in this study

\begin{tabular}{llc}
\hline Anthropometric parameters & AML cases $(\mathrm{n}=100)$ & Controls $(\mathrm{n}=100)$ \\
\hline Age (years) & $38.9 \pm 15.1$ & $39.9 \pm 12.06$ \\
\hline Minimum and maximum ages (years) & $19-82$ & $18-63$ \\
\hline Males (Gender) & $61(61 \%)$ & $54(54 \%)$ \\
\hline Females (Gender) & $39(39 \%)$ & $46(46 \%)$ \\
\hline
\end{tabular}

AML cases and control subjects were recruited based on the inclusion and exclusion criteria, as described in the previous publication (Farasani, 2019). The inclusion criteria of AML subjects were recruited based on the diagnosis of the AML with histopathological and cytogenetic confirmation, and informed consent signed by Saudi adults. The exclusion criteria of AML cases were patients diagnosed with other cancers, and unsigned consent form with non-Saudi subjects. The AML cases were diagnosed with bone-marrow examination, complete blood count and flow cytometry. Additionally, cytogenetics and fluorescent in situ hybridization tests were implemented for reconfirmation. The inclusion criteria of the healthy controls were not diagnosed with any specific type of cancers or other diseases. The exclusion criteria were non-Saudi subjects. Ethical grant was obtained from Ministry of Health affairs. This study was performed as per the Declaration of Helsinki.

\section{Sample selection}

From each patient ( $\mathrm{n}=200 ; 100$ AML cases and 100 healthy controls) $2 \mathrm{ml}$ of EDTA blood was collected and used for the DNA extraction and further use.

\section{Molecular analysis}

Genomic DNA extraction was carried out with specific kits used for separation of DNA and nanodrop was used to DNA quantification. Genotyping was performed towards V617F mutation in the $J A K 2$ gene using (F: TCCTCATCTATAGTCATGCTGAAA) and reverse (R:CTGACACCTAGCTGTGATCCTG) primers and polymerase chain reaction (PCR) was performed with the PCR master mix of $50 \mu$ microliters consisting of $4 \mu \mathrm{l}$ genomic DNA and $30 \mu \mathrm{l}$ PCR mixes, which contained 10X, $\mathrm{MgCl}_{2}$, dNTPs and 10x Taq DNA polymerases. The Master mix was supplemented by 10 pmoles of $2 \mu \mathrm{l}$ of forward and reverse primers followed by $12 \mu \mathrm{l}$ of distilled water. For the final amount of $50 \mu \mathrm{l}$, the PCR reaction has been standardized. V617F primers from previous investigations have been adopted. The initial denaturation was carried out at $95^{\circ} \mathrm{C}-5 \mathrm{~min}$., denaturation at $95^{\circ} \mathrm{C}-30 \mathrm{~s}$, annealing at $60^{\circ} \mathrm{C}-30 \mathrm{~s}$, extension at $72^{\circ} \mathrm{C}-45 \mathrm{~s}$ and final extension at $72^{\circ} \mathrm{C}-5$ min. with 35 cycles (Khan et al., 2015). The 305 bp PCR products were digested with $B S a X I$ enzyme at $37^{\circ} \mathrm{C}$ for 18 hours, whereupon samples were loaded on $3 \%$ agarose gel stained with ethidium bromide.

\section{Statistical analysis}

SPSS software (version 20) was used to examine the clinical data. Hardy-Weinberg Equilibrium (HWE) was used for comparing the observed and anticipated genotype frequencies using control subjects. The odds ratios, upper, and lower ranges of $95 \%$ confidence intervals $(95 \% \mathrm{CI})$ for V617T mutation in the JAK2 gene were used in the genotype differences between AML cases and controls. $p<0.05$ was considered as indicating the statistical significance (Khan et al., 2019).

\section{RESULTS}

This molecular analysis was carried in Riyadh, with 100 AML patients and 100 healthy control subjects. The mean age of AML cases was 38.9 \pm 15.1 years and $39.9 \pm 12.06$ years was documented for the healthy controls. Both groups showed similar ages with non-significant association $(p=0.60)$. The minimum age of AML cases and healthy controls was documented between 19 and 18 years of age and 82 and 63 years of age was documented as maximum ages, respectively. The male gender in AML cases was documented for $61 \%$ and $54 \%$ in the control groups and 39\% was documented for female subjects in AML cases and $46 \%$ in healthy controls. HWE was not in accordance with V617F mutation in (Table 1) the control subjects as none of the mutations was present. The genotype mutation frequencies between $\mathrm{VV}, \mathrm{VF}$ and $\mathrm{FF}$ were found to be $85 \%, 15 \%$ and $0 \%$ in the AML cases, whereas in the control subjects no mutation was documented either in VF or FF group 15\% of $\mathrm{F}$ allele and $85 \%$ of $\mathrm{V}$ allele mutations were documented between AML and, $100 \%$ of $\mathrm{V}$ allele mutation were present and $0 \%$ of $\mathrm{F}$ allele mutations were in the control

Table 2. JAK2 mutation analysis in AML patients

\begin{tabular}{llllll}
\hline JAK2 (rs77375493) & AML Cases $(\mathrm{n}=100)$ & Controls $(\mathrm{n}=100)$ & Odds Ratio & $(95 \% \mathrm{Cl})$ & $p$ value \\
\hline & $\mathrm{N}(\%)$ & $\mathrm{N}(\%)$ & & & Reference \\
\hline VV & $85(85 \%)$ & $100(100 \%)$ & Reference & Reference & 0.0001 \\
\hline VF & $15(15 \%)$ & $00(00 \%)$ & 18.79 & $2.442-144.6$ & 0.90 \\
\hline FF & $00(00 \%)$ & $00(00 \%)$ & 1.17 & $0.07-19.05$ & Reference \\
\hline V & $170(85 \%)$ & $200(100 \%)$ & Reference & Reference & $<0.0001$ \\
\hline F & $30(15 \%)$ & $00(00 \%)$ & 87.76 & $11.76-654.7$ & $<$ \\
\hline
\end{tabular}


subjects (Table 2). The genotypes present in this study were 100\% VV IVF vs VV; OR-18.79; (95\% CIs: 2.442144.6) and $p=0.0001$ and FF vs VV; OR-1.17; (95\%CIs: 0.07-19.05) and $p=0.90 ; \mathrm{F}$ vs V; OR-87.76; (95\%CIs: $11.76-654.7)$ and $p<0.0001]$ was significantly associated.

\section{DISCUSSION}

This study aimed to analyze rs77375493 (G>T) mutation in the $J A K 2$ gene, in the Saudi population diagnosed with AML. In this study, $15 \%$ of VF mutations were documented in AML cases. However, no FF mutations were observed in AML cases. None of the mutations were documented with VF and FF genotypes and $100 \%$ of VV genotypes were present in healthy controls. This study confirms that V617F mutation plays a major role in AML subjects. One of the strengths of this study was documented with 100 AML cases and 100 health subjects with age-matched subjects and one of the limitations of this study was not exhibiting the results of cytogenetic and FISH analysis. In this study, 60\% of VF mutations were found in male AML participants and $40 \%$ in female AML subjects. In AML patients, the male and female frequencies were $69 \%$ and $31 \%$, respectively.

AML is a deadly hematopoietic stem cell malignancy, resulting in a significant hematopoietic stem cell depletion, which further inhibits normal hematopoiesis. Early discovery and treatment for AML patients can help them survive, and a number of tests including cytogenetics and molecular analysis can help to estimate the likelihood of remission and survival. But because of many different molecular pathways of the disease, it is difficult to determine AML prognosis. Thus, a biomarker must be found that is more effective (Tong et al., 2020). JAK2 is a cytoplasmic tyrosine kinase that plays a crucial role in signal transduction of various hematopoietic receptors. The $J A K 2$ gene has discovered a gain-of-function mutation resulting in position 617 of valine-to-phenylalanine substitution (G1894T) (Malhan et al., 2014). JAK2 p.V617F is a missense mutation resulting in the activation of the JAK Signal Transducer and Transcription Pathway as a constituent of hematopoietic myeloid precursors in $>90 \%$ of polycythemia vera patients and roughly half of essential thrombocythemia and myelofibrosis individuals (Alghasham et al., 2016). Previous studies showed the positive and negative associations0 with V617F mutation and AML subjects in the global population (Aynardi et al., 2018; de Noronha et al., 2019; Illmer et al., 2007; Lee et al., 2006; Nahajevszky et al., 2006; Steensma et al., 2006; Vicente et al., 2007). There are no meta-analysis studies have been documented with V617F mutation in the JAK2 gene and AML diseases in the global population. Based on clinical trial results, Reddy and others (Reddy et al., 2012) studies confirmed the role of $J A K 2$ mutation as it indicates the feasibility and efficacy of JAK2 targeted approaches. Furthermore, there is a limited number of examples using JAK2 inhibitors as drugs due to the dose-dependent toxicity and the requirement of combined treatment.

In this study, using BsaXI restriction enzyme, PCR products were digested and randomly, $10 \%$ of PCR products were sequenced (Al-Otaiby et al., 2021). Previous studies, however, validated the false-positive and false-negative results, and one of the simplest techniques is to conduct the experiment with allele specific ARMS, and quantitative PCR analysis (Ali, 2020; Guo et al., 2020; McLornan et al., 2006). Skipping of additional PCR techniques could be one of the limitations of this study.

\section{CONCLUSION}

In conclusion, V617F mutation shows positive association with AML subjects in the Saudi population. Future studies should be performed in global population with a large sample size.

\section{Conflict of Interest}

There is no conflict of Interest regarding this article.

\section{REFERENCES}

Al-Otaiby M, Althnayan R, Binmethem A, AlEnezy RB, Alhadlg MA, Alaqeel A, AlQahtani SH, Ghufran N, Alotaibi AA, Alayed N, Ali Khan I (2021) The prevalence of Factor V Leiden (Arg506Gln) mutation in King Khalid University Hospital patients, 20172019. Nagoya J Med Sii 83: 407-417. https://doi.org/10.18999/ nagjms.83.3.407

Alghasham N, Alnouri Y, Abalkhail H, Khalil S (2016) Detection of mutations in JAK 2 exons $12-15$ by Sanger sequencing. Int I Lab Hematol 38: 34-41. https://doi.org/10.1111/ijlh.12425

Ali AEE (2020) Genetic polymorphisms of glutathione-S-transferase and $\mathrm{N}$-acetyltransferase-2 among Sudanese patients with acute lymphoblastic leukemia. Sudan University of Science \& Technology

Aynardi J, Manur R, Hess PR, Chekol S, Morrissette JJD, Babushok D, Hexner E, Rogers HJ, Hsi ED, Margolskee E, Orazi A, Hasserjian R, Bagg A (2018) JAK2 V617F-positive acute myeloid leukaemia (AML): a comparison between de novo AML and secondary AML transformed from an underlying myeloproliferative neoplasm. A study from the Bone Marrow Pathology Group. Br J Haematol 182: 78-85. https://doi.org/10.1111/bjh.15276

Botros SKA, El Gharbawi N, Shahin G, Al Lithy H, El Sherbiny M (2021) Impact of Cytochromes P450 3A4 and 2B6 gene polymorphisms on predisposition and prognosis of acute myeloid leukemia: an Egyptian case-control study. Egypt J Med Hum Genet 22: 1-10. https://doi.org/org/10.1186/s43042-021-00145-0

da Cunha Vasconcelos F, de Souza PS, Hancio T, de Faria FCC, Maia RC (2021) Update on drug transporter proteins in acute myeloid leukemia: Pathological implication and clinical setting. Crit Rev Oncol Hematol 160: 1-8. https://doi.org/10.1016/j.critrevonc.2021.103281

de Noronha TR, Mitne-Neto M, de Lourdes Chauffaille M (2019) JAK2-mutated acute myeloid leukemia: comparison of next-generation sequencing (NGS) and single nucleotide polymorphism array (SNPa) findings between two cases. Autops Case Rep 9: e2018084. https://doi.org/10.4322/acr.2018.084

Döhner H, Weisdorf DJ, Bloomfield CD (2015) Acute myeloid leukemia. N Engl J Med 373: 1136-1152. https://doi.org/10.1056/NEJMra1406184.

Farasani A (2019) Genetic variants of glutathione S-transferase and the risk of acute myeloid leukemia in a Saudi population. Saudi J Biol Sci 26: 1525-1530. https://doi.org/10.1016/j.sjbs.2018.12.011

Guo Y, Sun H, Zhang D, Zhao Y, Shi M, Yang M, Xing S, Fu X, Bin T, Lu B, Wu S, Xu X, Xu X, Chen Y, Zhao ZJ (2020) Development of a highly sensitive method for detection of FLT3D835Y. Biomark. Res 8: 30. https://doi.org/10.1186/s40364-020-00210-7

Hernandez-Valladares M, Wangen R, Aasebø E, Reikvam H, Berven FS, Selheim F, Bruserud $\varnothing$ (2021) Proteomic studies of primary acute myeloid leukemia cells derived from patients before and during disease-stabilizing treatment based on all-trans retinoic acid and valproic acid. Cancers (Basel) 13: 2143. https://doi.org/10.3390/cancers13092143

Illmer T, Schaich M, Ehninger G, Thiede C (2007) Tyrosine kinase mutations of JAK2 are rare events in AML but influence prognosis of patients with CBF-leukemias. Haematologica 92: 137-138. https:// doi.org/10.3324/haematol.10489

Khan IA, Jahan P, Hasan Q, Rao P (2015) Relationship between PTEN and gestational diabetes in Asian Indians womens. Journ of Health Specialties 3: 184-187. https://doi.org/10.4103/1658600X.159910

Khan IA, Jahan P, Hasan Q, Rao P (2019) Genetic confirmation of T2DM meta-analysis variants studied in gestational diabetes mellitus in an Indian population. Diabetes Metab Syndr 13: 688-694. https:// doi.org/10.1016/j.dsx.2018.11.035

Khan IA, Vattam KK, Jahan P, Hasan Q, Rao P (2016) Importance of glucokinase $-258 \mathrm{G} / \mathrm{A}$ polymorphism in Asian Indians with posttransplant and type 2 diabetes mellitus. Intractable Rare Dis Res 5: 25-30. https://doi.org/10.5582/irdr.2015.01040

Lee JW, Kim YG, Soung YH, Han KJ, Kim SY, Rhim HS, Min WS, Nam SW, Park WS, Lee JY, Yoo NJ, Lee SH (2006) The JAK2 V617F mutation in de novo acute myelogenous leukemias. Oncogene 25: 1434-1436. https://doi.org/10.1038/sj.onc.1209163 
Levine RL, Loriaux M, Huntly BJ, Loh ML, Beran M, Stoffregen E, Berger R, Clark JJ, Willis SG, Nguyen KT, Flores NJ, Estey E, Gattermann N, Armstrong S, Look AT, Griffin JD, Bernard OA, Heinrich MC, Gilliland DG, Druker B, Deininger MW (2005) The JAK2V617F activating mutation occurs in chronic myelomonocytic leukemia and acute myeloid leukemia, but not in acute lymphoblastic leukemia or chronic lymphocytic leukemia. Blood 106: 3377-3379. https://doi.org/10.1182/blood-2005-05-1898

Malhan H, Alzahrani H, Elgohary GM, Owaidah T, Aslam M, Mohamed SY (2014) Clinical and laboratory presentations of Janus Kinase II-positive patients in Saudi population. Journ of App Hem 5: 133-140. https://doi.org/10.4103/1658-5127.146947

McLornan D, Percy M, McMullin MF (2006) JAK2 V617F: a single mutation in the myeloproliferative group of disorders. Ulster Med J 75: 112-119

Nahajevszky S, Andrikovics H, Matrai Z, Lovas N, Lueff S, Masszi $\mathrm{T}$ (2006) Clinical characteristics of JAK2 V617F mutation positive acute myeloid leukemia. Blood 108: 4508. https://doi.org/10.1182/ blood.V108.11.4508.4508

Reddy MM, Deshpande A, Sattler M (2012) Targeting JAK2 in the therapy of myeloproliferative neoplasms. Expert Opin Ther Targets 16: 313-324. https://doi.org/10.1517/14728222.2012.662956

Sariani OK, Eghbalpour S, Kazemi E, Buzhani KR, Zaker F (2021) Pathogenic and therapeutic roles of cytokines in acute myeloid leukemia. Cytokine 142: 155508. https://doi.org/10.1016/j. cyto.2021.155508
Sasaki K, Ravandi F, Kadia TM, DiNard, CD, Short NJ, Borthakur $G$, et al (2021) De novo acute myeloid leukemia: A population-based study of outcome in the United States based on the Surveillance, Epidemiology, and End Results (SEER) database, 1980 to 2017. Cancer 127:2049-2061. https://doi.org/10.1002/cncr.33458

Steensma DP, McClure R, Karp J, Tefferi A, Lasho T, Powell $\mathrm{H}$ et al (2006) JAK2 V617F is a rare finding in de novo acute myeloid leukemia, but STAT3 activation is common and remains unexplained. Leukemia 20: 971-978. https://doi.org/10.1038/sj.leu.2404206

Tong L, Li X, Hu Y, Liu T (2020) Recent advances in FLT3 inhibitors for acute myeloid leukemia. Future Med Chem 12: 961-981. https:// doi.org/10.4155/fmc-2019-0365

Vicente C, Vázquez I, Marcotegui N, Conchillo A, Carranza C, Rivell G, Bandrés E, Cristobal I, Lahortiga I, Calasanz MJ, Odero MD (2007) JAK2-V617F activating mutation in acute myeloid leukemia: prognostic impact and association with other molecular markers. Leukemia 21: 2386-2390. https://doi.org/10.1038/sj.leu.2404812

Yuan Y, Wu Q, Zhao J, Feng Z, Dong J, An M, Wu G, Qin F, Zhao L (2021) Investigation of pathogenesis and therapeutic targets of acute myeloid leukemia based on untargeted plasma metabolomics and network pharmacology approach. J Pharm Biomed Anal 195: 113824. https://doi.org/10.1016/j.jpba.2020.113824 